\title{
Pesticidal and Mosquitocidal Activities of Clausena excavata Burm. F. (Rutaceae) against Spodoptera litura (Fab.) (Noctuidae: Lepidoptera) and Aedes aegypti L., Anopheles stephensi Liston, and Culex quinquefasciatus Say. (Diptera: Culicidae)
}

\author{
Mathivanan Thangarasu, Krishnappa Kaliyamoorthy, and Elumalai Kuppusamy \\ Unit of Entomotoxicity, Department of Advanced Zoology \& Biotechnology, Government Arts College (Autonomous), Nandanam, \\ Chennai, Tamilnadu 600 035, India \\ Correspondence should be addressed to Elumalai Kuppusamy; professorelumalai@gmail.com
}

Received 26 April 2014; Revised 23 July 2014; Accepted 23 July 2014; Published 10 September 2014

Academic Editor: Cleber Galvão

Copyright (c) 2014 Mathivanan Thangarasu et al. This is an open access article distributed under the Creative Commons Attribution License, which permits unrestricted use, distribution, and reproduction in any medium, provided the original work is properly cited.

\begin{abstract}
The aim of this paper is to evaluate the larvicidal and ovicidal activities of hexane, diethyl ether, dichloromethane, ethyl acetate, and methanol extract of Indian medicinal plant, Clausena excavata, at different concentrations against lepidopteran agricultural field pest, Spodoptera litura (Lepidoptera: Noctuidae), and Aedes aegypti, Anopheles stephensi, and Culex quinquefasciatus (Diptera: Culicidae). Twenty-five early fourth instar larvae of S. litura and A. aegypti, An. stephensi and C. quinquefasciatus were exposed to various concentrations and were assayed in the laboratory by using specific protocols. The $24 \mathrm{~h} \mathrm{LC}_{50}$ and $\mathrm{LC}_{90}$ values of the C. excavata leaf extract was determined by probit analysis. The ovicidal activity were determined against S. litura and A. aegypti, An. stephensi, and C. quinquefasciatus and was assessed $120 \mathrm{hrs}$ after treatment. Results of this study show that the selected Indian medicinal plant C. excavata may be a potential source of natural larvicidal and ovicidal activities against selected pest and vector mosquitoes.
\end{abstract}

\section{Introduction}

Spodoptera litura (Fab.) is a lepidopteran polyphagous pest, widely distributed throughout India. It has a wide range of hosts, feeding on 180 plant species worldwide, of which more than 60 species are known from India. The larvae of this pest can defoliate many economically important crops possessing a high dispersal capability. This pest has often generated high levels of agricultural losses which accounts for 69 percent reduction in yield. Traditional farmers have been practicing synthetic pesticides to eliminate $S$. litura and hence it has developed resistance against almost all the commonly used pesticides in several countries [1-6].

Most of the dipteran insects generally and mosquitoes in particular threaten the health and life of humans and animals often due to the transmission of agents of severe diseases like malaria, dengue fever, yellow fever, filariasis, and Japanese encephalitis that cause millions of deaths every year [7]. Mosquito bite also cause allergic responses in humans that include local skin and systemic reactions such as angioedema $[8,9]$. Aedes aegypti (Linn.) spreads arbovirus responsible for dengue fever and its prevalence is common to Southeast Asia, the Pacific island area, Africa, and the Americas. The disease remains endemic in more than 100 developing tropical countries and its control is a major goal for improved worldwide health [10]. Anopheles stephensi (Liston) is the common vector of malaria in India and other West Asian countries. Malaria remains one of the most prevalent diseases in the tropical world. With 200 million to 450 million infections annually worldwide, it causes up to 2.7 million deaths $[11,12]$. Culex quinquefasciatus (Say.) is widely distributed in tropical and subtropical countries infecting around 120 million people, of which 40 million people show chronic manifestation of lymphatic filariasis [13-15]. 
To reduce the incidence of different mosquito borne diseases such as malaria, filariasis, Japanese encephalitis, and dengue, control of mosquito population is a very important and effective step.

Pest and Mosquito control has been becoming increasingly difficult because of the indiscriminate uses of synthetic chemical insecticides which have an adverse impact on the environment and disturb ecological balance. Majority of the chemical pesticides are harmful to men and animals, some of which are not easily degradable and spread toxic effects [16]. These problems have highlighted the need for the development of new strategies for selective mosquito control [17]. The plant product of phytochemical is used as insecticides for killing larvae or adult mosquitoes or as repellents for protection against mosquito bites $[18,19]$. Plants may be a source of alternative agents for control of pest and mosquitoes because they are rich in bioactive chemicals, are active against a limited number of species including specific target insects, and are biodegradable. They are potentially suitable for use in Integrated Pest Management programs [20, 21]. Clausena excavata Burm. F. (Rutaceae) (C. excavata) is a medicinal plant which is used in folklore medicine for treatment of cold, malaria, AIDS, dermatopathy, abdominal pain, and snake-bite. C. excavata showed diverse therapeutic activities which are antibacterial, antifungal, antiplatelet, antiplasmodial, antitumor, antinociceptive, immunomodulatory, antimycobacterial, and anti-HIV-1 activities [22]. In view of the recently increased interest in developing plant origin insecticides as an alternative to chemical insecticide, this study was undertaken to assess the larvicidal and ovicidal potential of the hexane, diethyl ether, dichloromethane, ethyl acetate, and methanol extract of C. excavata against medically important vector mosquitoes and agricultural field pest.

\section{Material and Methods}

2.1. Plants Collection and Solvent Extraction. The plant leaves C. excavata were collected from in and around Yercaud hill station (11.77940N, 78.20340E) Salem District of the Tamilnadu, India. The leaves were collected during June 2013-January 2014 and brought to the laboratory where they were washed thoroughly with tap water and kept in sunlight for 45 minutes for the complete evaporation of water and then shade dried on blotting paper spread at room temperature $\left(28 \pm 2^{\circ} \mathrm{C}\right)$. The dried plant material was powdered using electric blender and extracted with selected solvent using Soxhlet apparatus. The solvent from the crude extract was evaporated using rotary evaporator at $45^{\circ} \mathrm{C}$ until the complete evaporation of solvent; the crude extract was weighed and stored in an aseptic amber bottle vials at $4^{\circ} \mathrm{C}$ in the refrigerator.

2.2. Pest Rearing. The armyworm, S. litura, was cultured and maintained in the laboratory on castor leaves (Ricinus communis L.). Rearing conditions were 12 hours photo regime at $28 \pm 2^{\circ} \mathrm{C}$ and $75 \pm 5 \%$ relative humidity. The insect culture was continuously refreshed with wild moths captured on a light trap in the vicinity of the agricultural farm of Koothur
Village, Sirkali Taluk, Nagapattinam District. Generally hale and healthy and uniform sized fourth instar larvae, fresh eggs, and newly emerged adult moths of cultured species were used for the experiments.

2.3. Vector Rearing. The mosquitoes, Aedes aegypti, Anopheles stephensi, and Culex quinquefasciatus, were reared in the Department of Zoology, Government Arts College, Nandanam. The larvae were fed on dog biscuits and yeast powder in the 3:1 ratio. Adults were provided with 10\% sucrose solution and one-week-old chick for blood meal. Mosquitoes were held at $(28 \pm 2)^{\circ} \mathrm{C}, 70 \%-85 \%$ relative humidity $(\mathrm{RH})$, with a photo period of $14 \mathrm{~h}$ light, $10 \mathrm{~h}$ dark.

2.4. Larvicidal Activity of Pest. For the evaluation of larvicidal activity, $100-500 \mathrm{ppm}$ concentrations were used against $S$. litura larvae. Petioles of the leaves were tied with wet cotton plug to avoid early drying and placed in plastic trough $(29 \mathrm{~cm}$ $\times 8 \mathrm{~cm}$ ). Twenty prestarved $(4 \mathrm{~h})$ fourth instar larvae of tested organism were introduced individually and covered with muslin cloth. Five replicates were maintained and the number of dead larvae after $48 \mathrm{~h}$ was recorded and the percentage of larval mortality was calculated using Abbott's formula (1925) [23].

2.5. Larvicidal Activity of Vector. The larvicidal activity of selected plant extracts was evaluated as per the protocol [24]. Based on the wide range and narrow range test, plant extracts ranging from 100 to $500 \mathrm{ppm}$ were prepared and they were tested against the freshly moulted ( $0-6$ hrs) fourth instar larvae of selected mosquito species. Plant extracts were dissolved in $1 \mathrm{~mL}$ DMSO and then diluted in $249 \mathrm{~mL}$ of dechlorinated tap water to obtain each of the desired concentrations. The larval mortality was observed and recorded after $24 \mathrm{~h}$ of treatment. For each experiment, five replicates were maintained and the $\mathrm{LC}_{50}$ value was calculated by using probit analysis [25].

2.6. Ovicidal Activity of Pest. For ovicidal activity, scales from the egg masses of $S$. litura were carefully removed using fine camel brush. 500 eggs were separated into five lots each having 100 eggs and dipped in 100-500 ppm concentrations of plant extracts and control eggs were treated without the plant extracts. Number of eggs hatched in control and treatments were recorded and the percentage of ovicidal activity was calculated using Abbott's formula [23].

2.7. Ovicidal Activity of Vector. The method of Su and Mulla [26] was slightly modified and used to test the ovicidal activity. The various concentrations as stated in the previous experiments were prepared from the stock solution. Eggs exposed to DMSO in water served as control. After treatment, the eggs from each concentration were individually transferred to distilled water cups for hatching assessment after counting the eggs under a microscope. The eggs mortality was assessed after $48 \mathrm{hrs}$. Five replications were maintained for each experiment. 
TABLE 1: Lethal activity of Clausena excavatadifferent extracts against 4th instar larvae of selected mosquitoes and pest species.

\begin{tabular}{|c|c|c|c|c|c|c|c|c|c|}
\hline \multirow{2}{*}{ Solvent tested } & \multirow{2}{*}{ Insects name } & \multirow{2}{*}{$\mathrm{LC}_{50}(\mathrm{ppm})$} & \multicolumn{2}{|c|}{ 95\% fiducial limit (ppm) } & \multirow{2}{*}{$\mathrm{LC}_{90}(\mathrm{ppm})$} & \multicolumn{2}{|c|}{ 95\% fiducial limit (ppm) } & \multirow{2}{*}{ Slope } & \multirow{2}{*}{$\chi^{2}$} \\
\hline & & & LCL & UCL & & LCL & UCL & & \\
\hline \multirow{4}{*}{ Hexane } & A. aegypti & 262.20 & 240.59 & 282.79 & 472.97 & 439.91 & 516.46 & 3.365 & 1.914 \\
\hline & An. stephensi & 258.21 & 235.40 & 279.69 & 480.47 & 445.52 & 526.99 & 3.212 & 0.854 \\
\hline & C. quinquefasciatus & 263.90 & 242.10 & 284.65 & 477.10 & 443.53 & 521.42 & 3.398 & 1.521 \\
\hline & S. litura & 266.55 & 244.99 & 287.17 & 477.97 & 444.70 & 521.75 & 3.359 & 1.014 \\
\hline \multirow{4}{*}{ Diethyl ether } & A. aegypti & 253.82 & 218.00 & 28638 & 465.63 & 417.09 & 540.90 & 3.369 & 2.795 \\
\hline & An. stephensi & 254.54 & 233.63 & 274.35 & 454.14 & 423.40 & 494.16 & 3.590 & 1.152 \\
\hline & C. quinquefasciatus & 263.58 & 242.55 & 283.69 & 467.99 & 436.06 & 509.06 & 3.480 & 1.071 \\
\hline & S. litura & 273.31 & 242.06 & 303.30 & 466.88 & 422.46 & 533.42 & 3.689 & 2.693 \\
\hline \multirow{4}{*}{ Dichloromethane } & A. aegypti & 266.44 & 227.29 & 302.85 & 473.43 & 420.07 & 560.78 & 3.490 & 3.571 \\
\hline & An. stephensi & 267.65 & 233.77 & 299.39 & 480.83 & 432.38 & 555.09 & 3.358 & 2.627 \\
\hline & C. quinquefasciatus & 267.75 & 237.58 & 296.38 & 467.01 & 423.98 & 530.23 & 3.578 & 2.370 \\
\hline & S. litura & 262.45 & 229.87 & 292.90 & 465.30 & 419.88 & 533.69 & 3.507 & 2.610 \\
\hline \multirow{4}{*}{ Ethyl acetate } & A. aegypti & 246.45 & 186.48 & 297.23 & 448.27 & 381.52 & 583.52 & 3.787 & 6.989 \\
\hline & An. stephensi & 256.62 & 205.36 & 302.17 & 461.18 & 398.77 & 577.35 & 3.525 & 5.574 \\
\hline & C. quinquefasciatus & 245.23 & 197.91 & 286.32 & 448.88 & 391.93 & 548.93 & 3.646 & 4.649 \\
\hline & S. litura & 251.38 & 195.04 & 300.01 & 459.06 & 393.23 & 587.89 & 3.598 & 6.188 \\
\hline \multirow{4}{*}{ Methanol } & A. aegypti & 227.23 & 151.99 & 285.55 & 413.84 & 343.53 & 576.90 & 4.258 & 10.001 \\
\hline & An. stephensi & 232.13 & 157.25 & 290.06 & 431.41 & 359.29 & 596.31 & 4.059 & 9.126 \\
\hline & C. quinquefasciatus & 227.90 & 165.87 & 277.51 & 419.39 & 356.23 & 547.07 & 3.995 & 7.232 \\
\hline & S. litura & 228.46 & 154.56 & 285.91 & 416.26 & 346.56 & 575.06 & 4.070 & 9.682 \\
\hline
\end{tabular}

$\mathrm{LC}_{50}$ : lethal concentration brings out $50 \%$ mortality and $\mathrm{LC}_{90}$ : lethal concentration brings out $90 \%$ mortality. LCL: lower confidence limit; UCL: upper confidence limit; slope and chi-square.

2.8. Statistical Analysis. The average mortality data were subjected to probit analysis for calculating $\mathrm{LC}_{50}, \mathrm{LC}_{90}$, and other statistics such as chi-square, slope, and regression values were calculated by using the software Statistical Package for Social Sciences (SPSS) version 18.0 for windows; significance level was set at $P<0.05$.

\section{Results}

The larvicidal activity of different solvent extract of $C$. excavata tested against different vector mosquitoes and a field pest is shown in Figure 1. Dose dependent larval mortality was observed with the present experiment; that is, as the concentration increases the rate of larval mortality was also increased. Among the various concentrations tested, $500 \mathrm{ppm}$ showed remarkable activity and among the solvents, methanol extract was found to have significant activity. Thus, the $\mathrm{LC}_{50}$ and $\mathrm{LC}_{90}$ were significantly lower than other solvent extracts (Table 1). Similar trends were also observed with the ovicidal activity. Maximum percentage of eggs was killed when they were exposed to $500 \mathrm{ppm}$ concentration of the methanol extract as it is evidenced from Figure 2.

\section{Discussion}

This study showed that different extracts of $C$. excavata have significant larvicidal and ovicidal activities against $A$. aegypti, An. stephensi, C. quinquefasciatus, and S. litura. These results are comparable with an earlier report by Mathivanan et al., [27] who reported similar results with methanol extract of the plant Ervatamia coronaria which showed promising larvicidal and ovicidal activity against Anopheles stephensi. Recently, Ojewole et al. [28] reported a pronounced larvicidal activity from root, bark, stem, and leaf extracts of Senna didymo botrya against the larvae of Anopheles fluviatilis. Methanolic leaf extracts of Momordica charantia, Trichosanthes anguina, Luffa acutangula, Benincasa cerifera, and Citrullus vulgaris were toxic to late third instar larvae of C. quinquefasciatus [29]. In tropical countries, plants are known to possess larvicidal, ovicidal, and adulticidal activities [30]. The findings of the present investigation revealed that $C$. excavata possessed remarkable larvicidal and ovicidal activities against selected pest and mosquitoes. Earlier, several authors reported that the crude extracts of various plants are effective towards the control of various species of mosquitoes either at larval stage or at egg stage [31-35]. Recently, the leaf extracts of Hyptis suaveolens were found to have remarkable effect on Anopheles gambiae [36]. To support the present findings earlier reports of various authors [37-42] showed that statistically significant larvicidal and ovicidal activities were recorded against the important lepidopteran field pest, S. litura.

\section{Conclusion}

The methanol extract of C. excavata at higher concentration showed maximum larvicidal and ovicidal activity against 

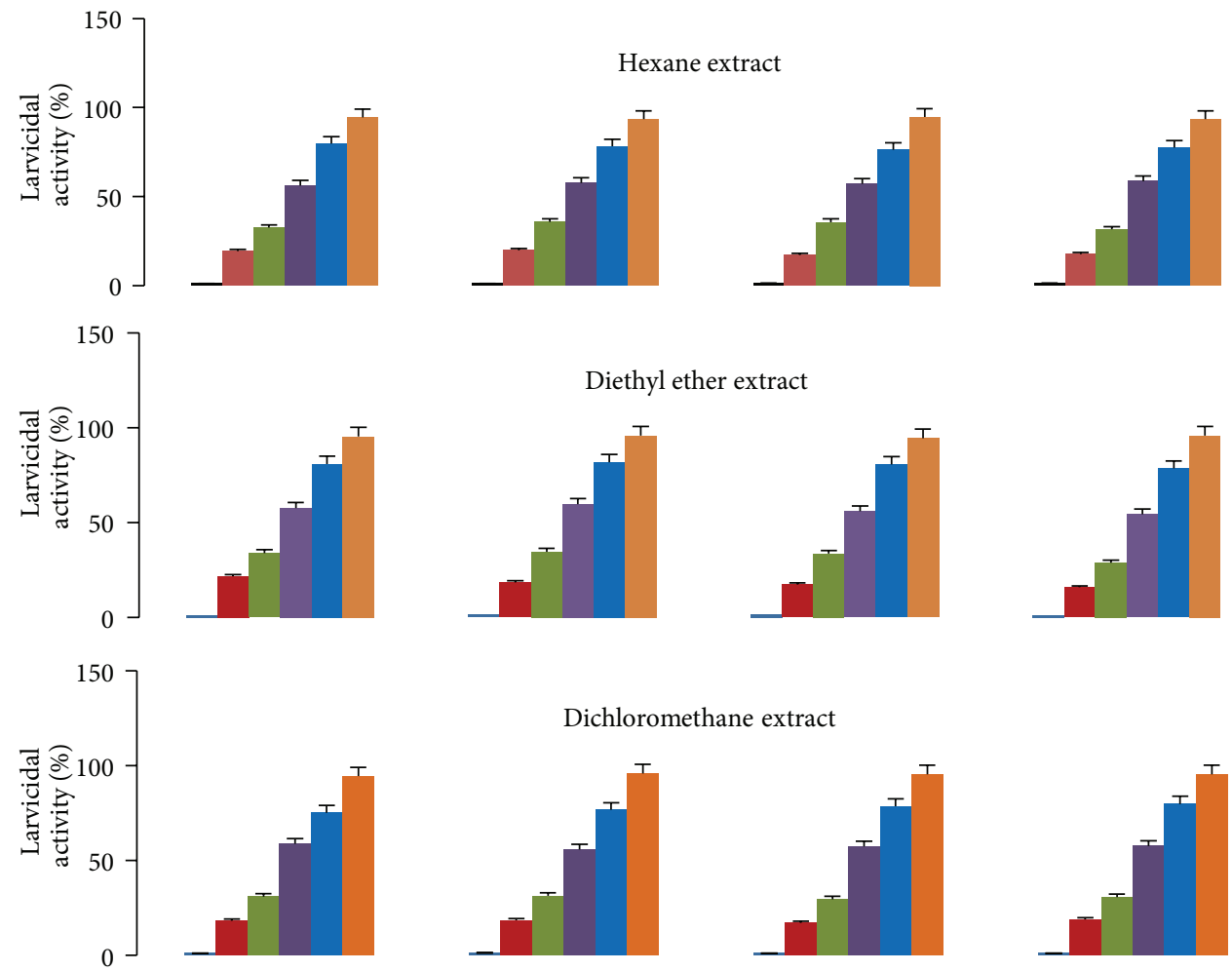

Dichloromethane extract
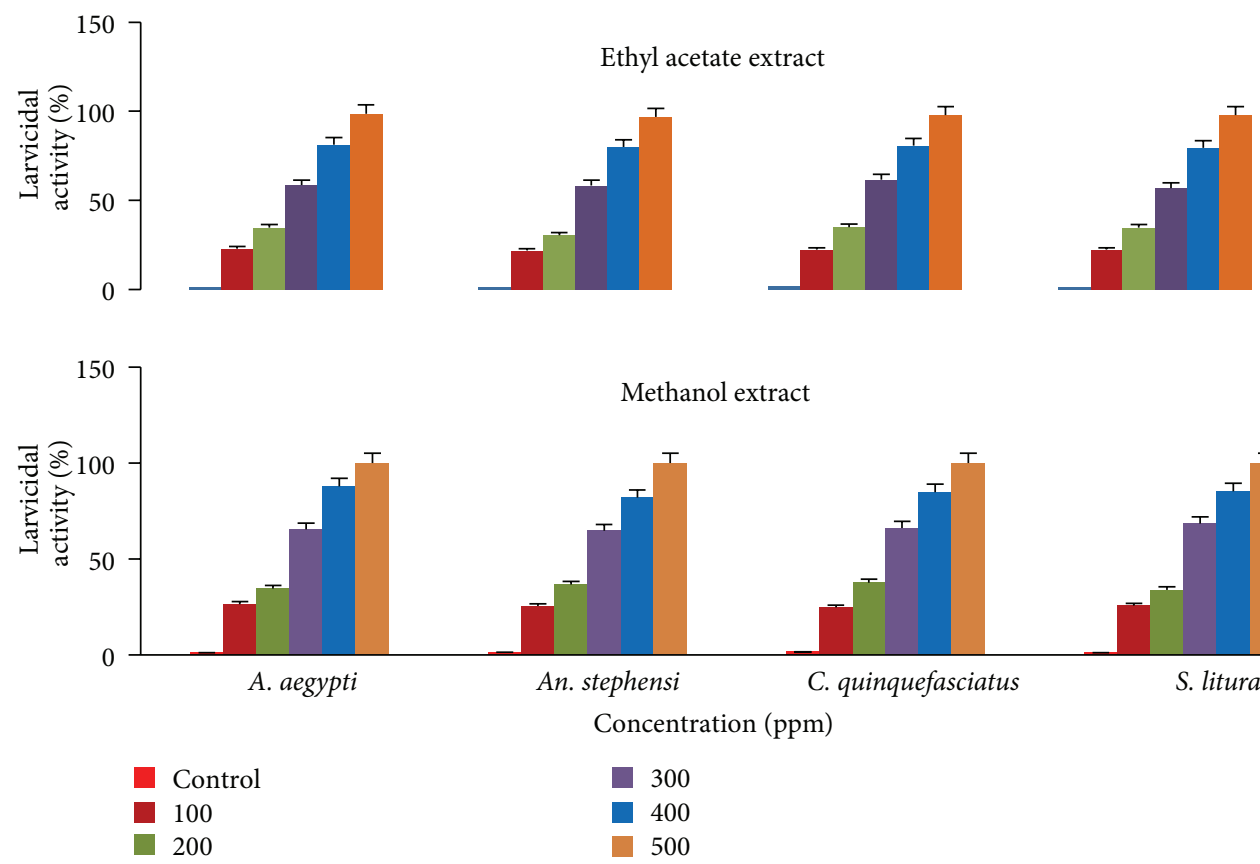

FIGURE 1: Larvicidal activity of different solvent extracts of Clausena excavata against 4 th instar larvae of selected mosquitoes and pest species.

tested mosquitoes and a field pest $S$. litura. Hence it is inferred that the methanol extract of Clausena excavata can be used further for the isolation of active molecules to develop a new botanical formulation and this may serve as an effective phytopesticides to control the vectors and pest in the near future. We are continuing to develop phytopesticides as a biocide for medically important vectors and an agricultural field pest.

\section{Conflict of Interests}

The authors declare that they have no conflict of interests. 

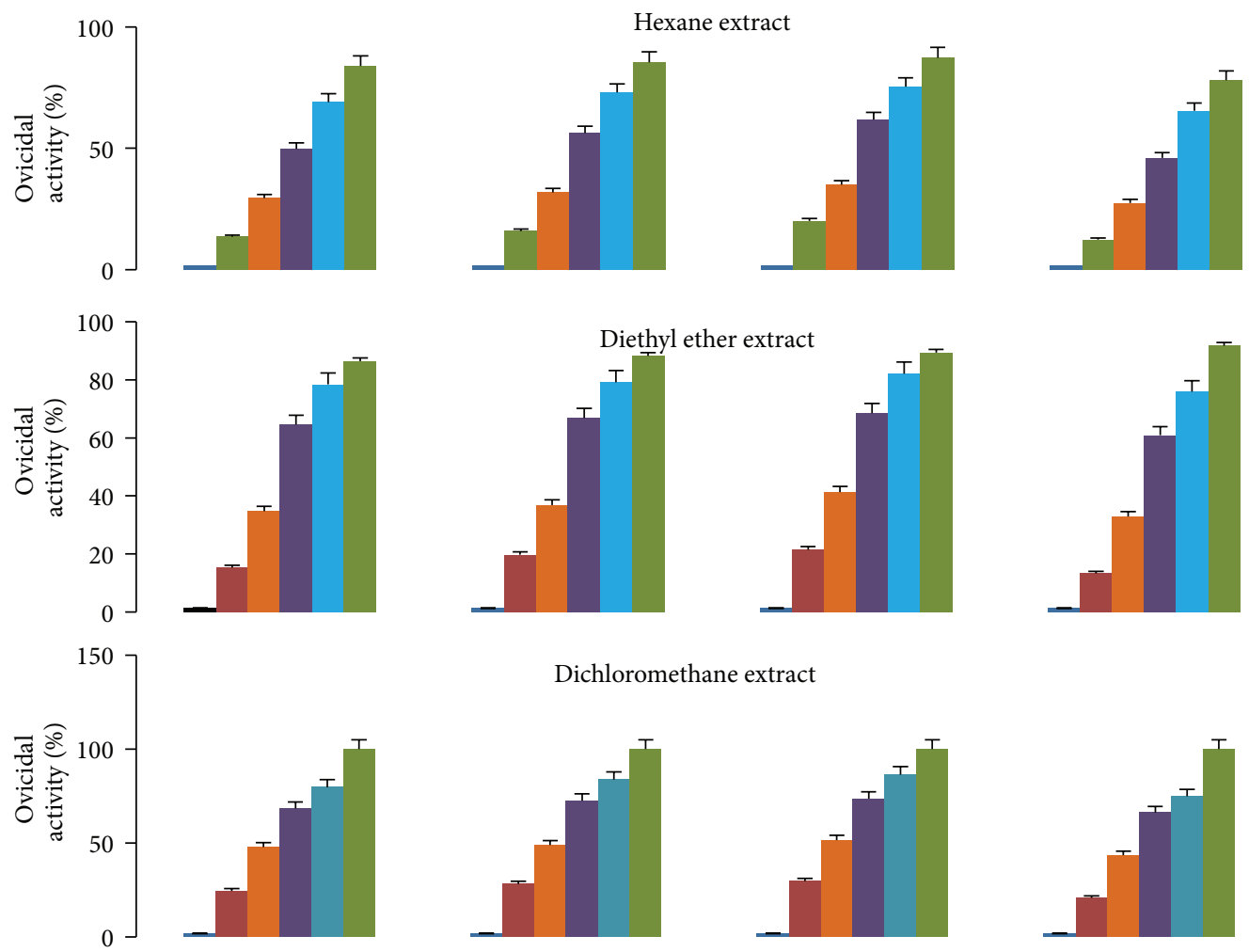

Dichloromethane extract
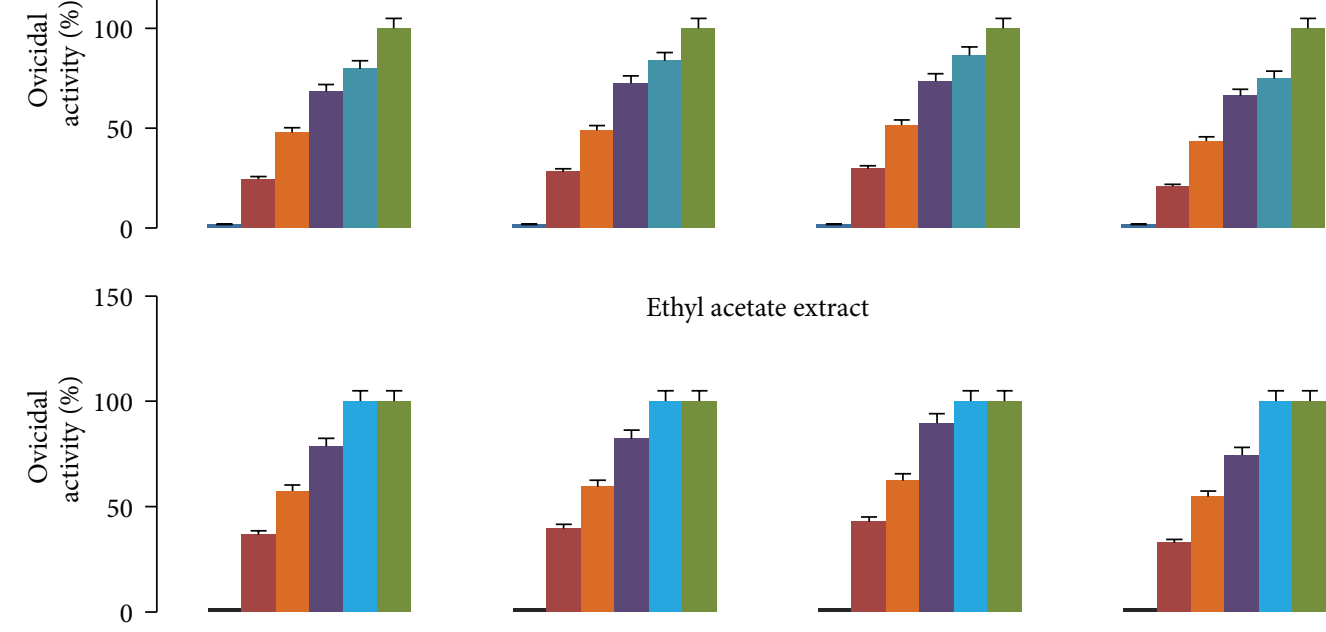

Ethyl acetate extract

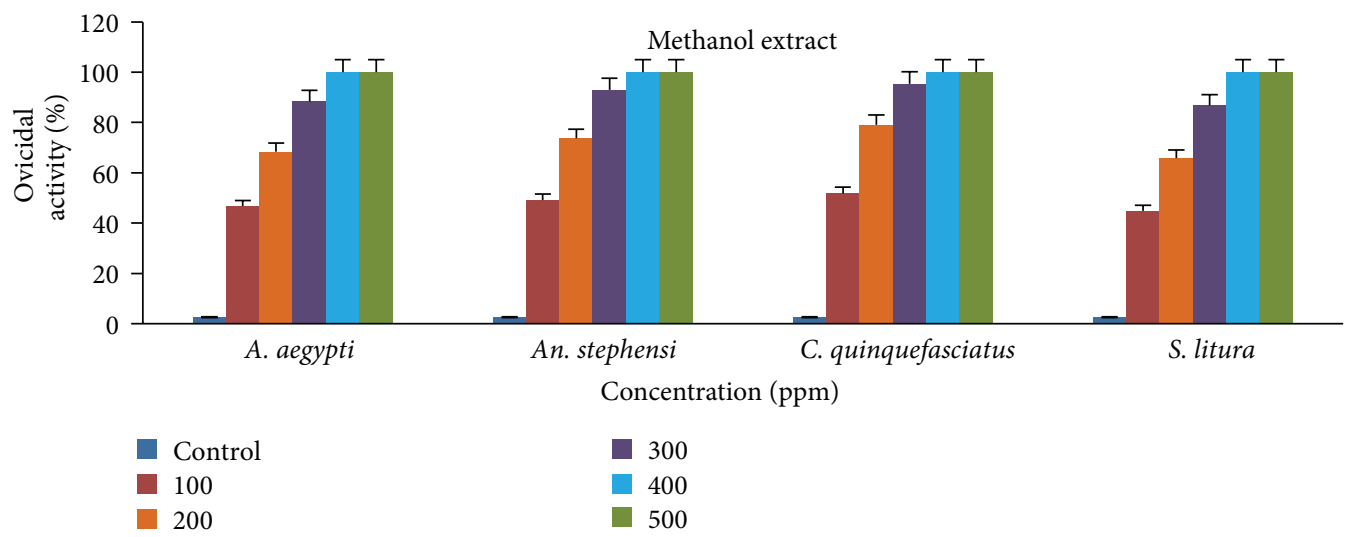

FIGURE 2: Ovicidal activity of different solvent extracts of Clausena excavata against the eggs of selected pest and vector mosquitoes.

\section{Acknowledgments}

Authors are gratefully thankful to Professor N. Kalaichelvi, Head of Department of Zoology The Principal, Government
Arts College (Autonomous), Nandanam, for their support and laboratory facilities provided. The authors are also thankful to University Grants Commission (UGC, New Delhi; Reference no. 42-583/2013 (SR)) for their financial assistance. 


\section{References}

[1] H. Tong, Q. Su, X. Zhou, and L. Bai, "Field resistance of Spodoptera litura (Lepidoptera: Noctuidae) to organophosphates, pyrethroids, carbamates and four newer chemistry insecticides in Hunan, China," Journal of Pest Science, vol. 86, no. 3, pp. 599-609, 2013.

[2] C. Zhou, Y. Q. Liu, W. L. Yu et al., "Resistance of Spodoptera exigua to ten insecticides in Shandong, China," Phytoparasitica, vol. 39, no. 4, pp. 315-324, 2011.

[3] M. Ahmad and M. Iqbal Arif, "Occurrence of insecticide resistance in field populations of Spodoptera litura (Lepidoptera: Noctuidae) in Pakistan," Crop Protection, vol. 26, no. 6, pp. 809817, 2007.

[4] N. Ramakrishnan, V. S. Saxena, and S. Dhingra, "Insecticideresistance in the population of Spodoptera litura (F.) in Andhra Pradesh," Pesticides, vol. 18, no. 9, pp. 23-27, 1984.

[5] M. Ahmad, A. H. Sayyed, M. A. Saleem, and M. Ahmad, "Evidence for field evolved resistance to newer insecticides in Spodoptera litura (Lepidoptera: Noctuidae) from Pakistan," Crop Protection, vol. 27, no. 10, pp. 1367-1372, 2008.

[6] S. Huang, J. Xu, and Z. Han, "Baseline toxicity data of insecticides against the common cutworm Spodoptera litura (Fabricius) and a comparison of resistance monitoring methods," International Journal of Pest Management, vol. 52, no. 3, pp. 209213, 2006.

[7] H. Mehlhorn, G. Schmahl, and J. Schmidt, "Extract of the seeds of the plant Vitex agnus castus proven to be highly efficacious as a repellent against ticks, fleas, mosquitoes and biting flies," Parasitology Research, vol. 95, no. 5, pp. 363-365, 2005.

[8] World Health Organization, Guidelines for Efficacy Testing of Mosquito Repellents for Human Skins, WHO/ HTM/NTD/ WHOPES/2009.4, WHO, Geneva, Switzerland, 2009.

[9] World Health Organisation, Malaria, WHO, Geneva, Switzerland, 2010, http://www.who.int/mediacentre/factsheets/ fs094/en/.

[10] C. Pancharoen, T. Tantawichien, C. Thisyakorn, W. Kulwichit, and U. Thisyakorn, "Dengue infection : a global concern," Journal of the Medical Association of Thailand, vol. 85, no. 1, pp. S25-S33, 2002.

[11] World Health Organization, "Report of the WHO informal consultation on the evaluation and testing of insecticides," Tech. Rep. CTD/WHO PES/IC/96.1, WHO, Geneva, Switzerland, 1996.

[12] World Health Organization, Pesticides and Their Application for the Control of Vectors and Pests of Public Health Importance, WHO Pesticides Evaluation Scheme, WHO/CDS/ WHOPES/ GCDPP/1, World Health Organization, 2006.

[13] World Health Organization, "Guidance on policy-making for integrated vector management," WHO/HTM/NTD/ VEM/2012.2.20, Avenue Appia, 1211 Geneva, Switzerland, 2012.

[14] K. Elumalai, S. Dhanasekaran, and K. Krishnappa, "Larvicidal activity of Saponin isolated from Gymnema sylvestre R. Br. (Asclepiadaceae) against Japanese Encephalitis vector, Culex tritaeniorhynchus Giles (Diptera: Culicidae)," European Review for Medical and Pharmacological Sciences, vol. 17, no. 10, pp. 1404-1410, 2013.

[15] K. Krishnappa and K. Elumalai, "Mosquitocidal properties of Basella rubra and Cleome viscosa against Aedes aegypti (Linn.) (Diptera:Culicidae)," European Review for Medical and Pharmacological Sciences, vol. 17, no. 9, pp. 1273-1277, 2013.
[16] G. K. Ghosh, Biopesticide and Integrated Pest Management, A. P. H. Publishing, New Delhi, India, 1991.

[17] K. Elumalai, S. Dhanasekaran, A. Anandan, K. Krishnappa, J. Gokulakrishnan, and A. Elangovan, "Mosquitocidal activities of Abrus precatorius L (Fabaceae) against chickungunya vector, Aedes aegypti (L.) and Japanese encephalitis vector, Culex tritaeniorhynchus (Giles) (Diptera:Culicidae)," International Journal of Current Research in Agriculture, vol. 2, no. 7, pp. 28-33, 2012.

[18] K. Krishnappa, S. Dhanasekaran, and K. Elumalai, "Larvicidal, ovicidal and pupicidal activities of Gliricidia sepium (Jacq.) (Leguminosae) against the malarial vector, Anopheles stephensi Liston (Culicidae: Diptera)," Asian Pacific Journal of Tropical Medicine, vol. 5, no. 8, pp. 598-604, 2012.

[19] A. Elangovan, S. Dhanasekaran, A. Anandan, K. Krishnappa, J. Gokulakrishnan, and K. Elumalai, "Larvicidal and ovicidal activities of Exacum pedunculatum (Linn.) (Gentinaceae) against a common malarial vector, Anopheles stephensi Liston (Diptera : Culicidae)," International Journal of Recent Scientific Research, vol. 3, no. 6, pp. 559-563, 2012.

[20] K. Krishnappa and K. Elumalai, "Abutilon indicum and Diplocyclos palmatus botanical extracts against ovicidal, pupicidal and repellent activities of Aedes aegypti, Anopheles stephensi and Culex quinquefasciatus (Diptera : Culicidae)," Asian Pacific Journal of Tropical Biomedicine, vol. 1, pp. 1-7, 2012.

[21] K. Krishnappa and K. Elumalai, "Toxicity of Aristolochia bracteata methanol leaf extract against selected medically important vector mosquitoes (Diptera: Culicidae)," Asian Pacific Journal of Tropical Disease, vol. 2, no. 2, pp. S553-S557, 2012.

[22] A. Sunthitikawinsakul, N. Kongkathip, B. Kongkathip et al., "Anti-HIV-1 limonoid: first isolation from Clausena excavata," Phytotherapy Research, vol. 17, no. 9, pp. 1101-1103, 2003.

[23] W. S. Abbott, "A method of computing the effectiveness of an insecticide," Journal of Economic Entomology, vol. 18, pp. 265266, 1925.

[24] World Health Organization, "Guidelines for laboratory and field testing of mosquito larvicides," Communicable Disease Control, Prevention and Eradication, WHO Pesticide Evaluation Scheme WHO/CDS/WHOPES/GCDPP/1.3, WHO, Geneva, Switzerland, 2005.

[25] D. J. Finney, Probit Analysis, London, UK, Cambridge University Press, 1979.

[26] T. Su and M. S. Mulla, "Ovicidal activity of neem products (Azadirachtin) against Culex tarsalis and Culex quinquefasciatus (Diptera: Culicidae)," Journal of the American Mosquito Control Association, vol. 14, no. 2, pp. 204-209, 1998.

[27] T. Mathivanan, M. Govindarajan, K. Elumalai, K. Krishnappa, and A. Ananthan, "Mosquito larvicidal and phytochemical properties of Ervatamia coronaria Stapf. (Family: Apocynaceae)," Journal of Vector Borne Diseases, vol. 47, no. 3, pp. 178-180, 2010.

[28] J. A. O. Ojewole, S. Rahim, and F. O. Shode, "Mosquito larvicidal properties of aqueous extract of Senna didymobotrya," Nigerian Journal of Natural Product and Medicine, vol. 4, pp. 46-47, 2000.

[29] K. Prabakar and A. Jebanesan, "Larvicidal efficacy of some Cucurbitacious plant leaf extracts against Culex quinquefasciatus (Say)," Bioresource Technology, vol. 95, no. 1, pp. 113-114, 2004.

[30] R. E. Trudel and A. Bomblies, "Larvicidal effects of Chinaberry (Melia azederach) powder on Anopheles arabiensis in Ethiopia," Parasites and Vectors, vol. 4, no. 1, article 72, 2011.

[31] A. A. Rahuman, G. Gopalakrishnan, P. Venkatesan, and K. Geetha, "Larvicidal activity of some Euphorbiaceae plant 
extracts against Aedes aegypti and Culex quinquefasciatus (Diptera: Culicidae)," Parasitology Research, vol. 102, no. 5, pp. 867-873, 2008.

[32] A. A. Rahuman, A. Bagavan, C. Kamaraj et al., "Evaluation of indigenous plant extracts against larvae of Culex quinquefasciatus Say (Diptera: Culicidae)," Parasitology Research, vol. 104, no. 3, pp. 637-643, 2009.

[33] S. Mandal, "Effect of azadirachta indica A. Juss (Meliaceae) seed oil and extract against culex quinquefasciatus say (Diptera: Culicidae) larval susceptibility of Indian subcontinent," Macedonian Journal of Medical Sciences, vol. 4, no. 1, pp. 5-11, 2011.

[34] P. Tandon and A. Sirohi, "Assessment of larvicidal properties of aqueous extracts of four plants against Culex quinquefasciatuslarvae," Jordan Journal of Biological Science, vol. 3, pp. 1-6, 2010.

[35] A. M. Elimam, K. H. Elmalik, and F. S. Ali, "Efficacy of leaves extract of Calotropis procera Ait. (Asclepiadaceae) in controlling Anopheles arabiensis and Culex quinquefasciatus mosquitoes," Saudi Journal of Biological Sciences, vol. 16, no. 2, pp. 95-100, 2009.

[36] N. Ivoke, O. Fabian Chukwuemenam, and L. O. Owoicho, "Evaluation of ovicidal and larvicidal effects of leaf extracts of Hyptis suaveolens (L) (Lamiaceae) against Anopheles gambiae (Diptera: Anophelidae) complex," Animal Research Institute, vol. 6, no. 3, pp. 1072-1076, 2009.

[37] R. Pavela, "Antifeedant activity of plant extracts on Leptinotarsa decemlineata Say. and Spodoptera littoralis Bois. larvae," Industrial Crops and Products, vol. 32, no. 3, pp. 213-219, 2010.

[38] M. Hamshou, E. J. M. van Damme, and G. Smagghe, "Entomotoxic effects of fungal lectin from Rhizoctonia solani towards Spodoptera littoralis," Fungal Biology, vol. 114, no. 1, pp. 34-40, 2010.

[39] E. Muñoz, C. Lamilla, J. C. Marin, J. Alarcon, and C. L. Cespedes, "Antifeedant, insect growth regulatory and insecticidal effects of Calceolaria talcana (Calceolariaceae) on Drosophila melanogaster and Spodoptera frugiperda," Industrial Crops and Products, vol. 42, no. 1, pp. 137-144, 2013.

[40] D. Haouas, G. Flamini, M. Ben Halima-Kamel, and M. H. Ben Hamouda, "Feeding perturbation and toxic activity of five Chrysanthemum species crude extracts against Spodoptera littoralis (Boisduval) (Lepidoptera; Noctuidae)," Crop Protection, vol. 29, no. 9, pp. 992-997, 2010.

[41] K. Y. Wang, Y. Zhang, H. Y. Wang, X. M. Xia, and T. X. Liu, "Influence of three diets on susceptibility of selected insecticides and activities of detoxification esterases of Helicoverpa assulta (Lepidoptera: Noctuidae)," Pesticide Biochemistry and Physiology, vol. 96, no. 1, pp. 51-55, 2010.

[42] J. Gokulakrishnan, K. Krishnappa, and K. Elumalai, "Effect of plant oil formulation against armyworm, Spodoptera litura (Fab.) cotton bollworm, Helicoverpa armigera (Hub.) and fruit borer, Earias vitella (Fab.) (Lepidoptera: Noctuidae)," International Journal of Current Life Sciencs, vol. 2, no. 1, pp. 1-4, 2012. 

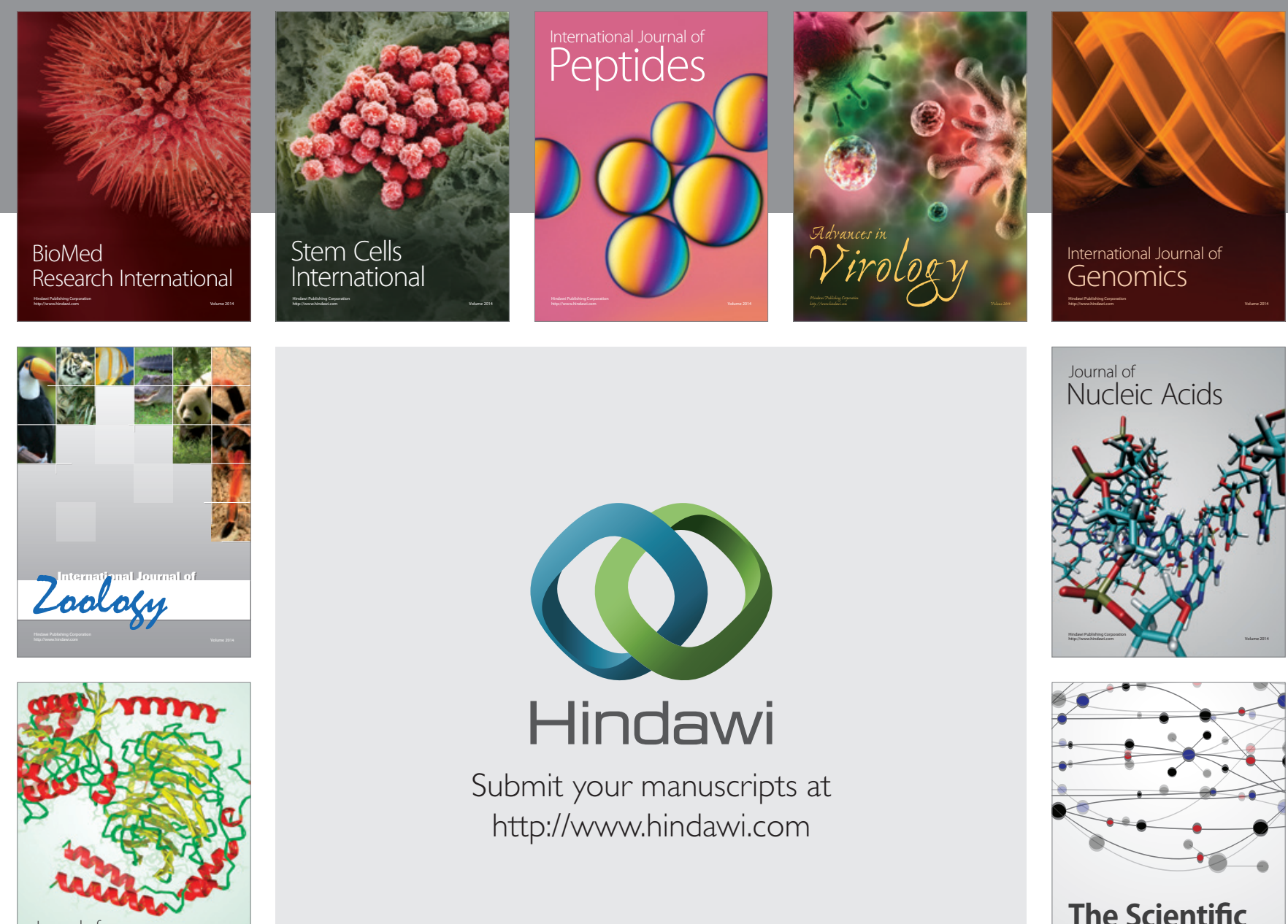

Submit your manuscripts at

http://www.hindawi.com

Journal of
Signal Transduction
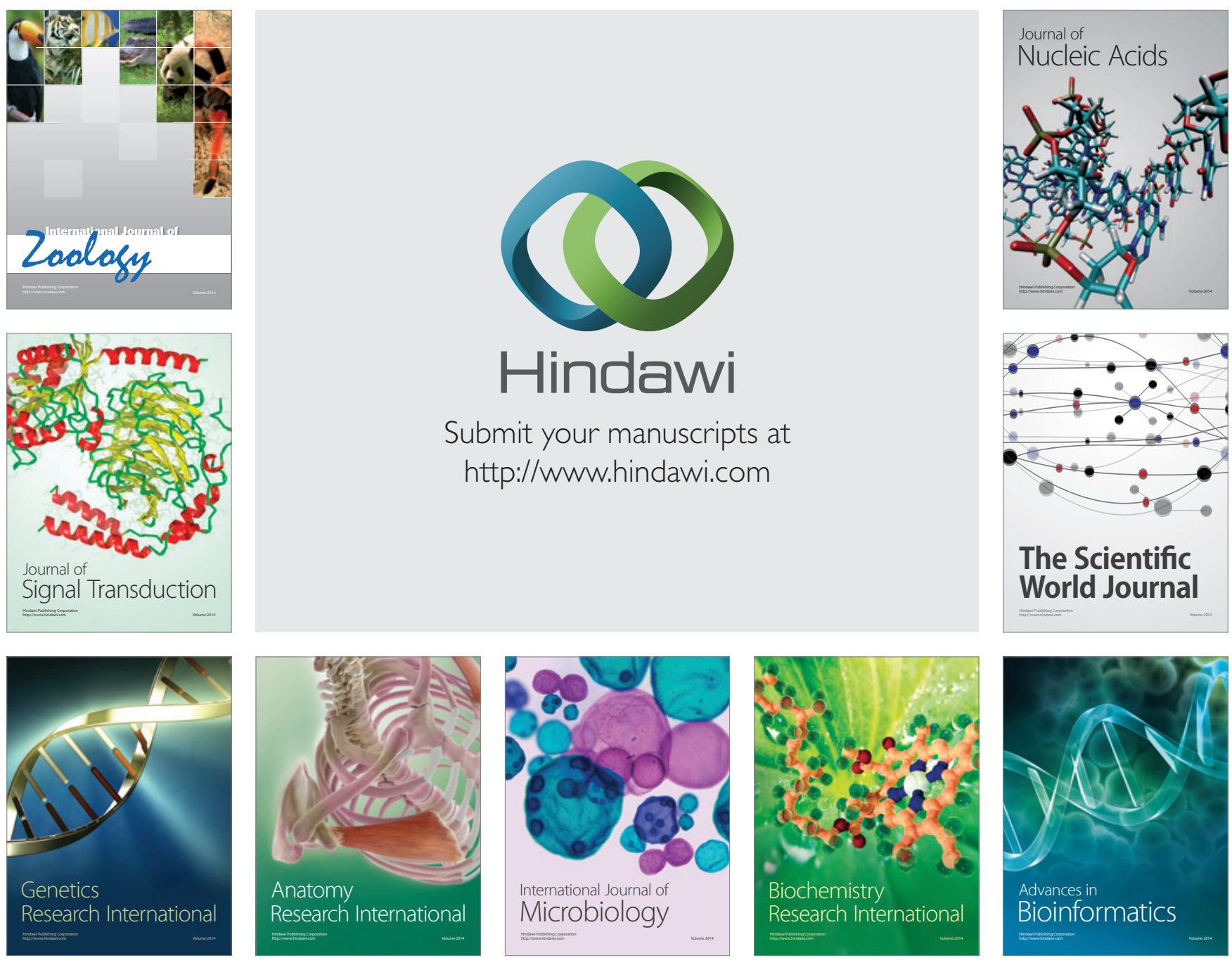

The Scientific World Journal
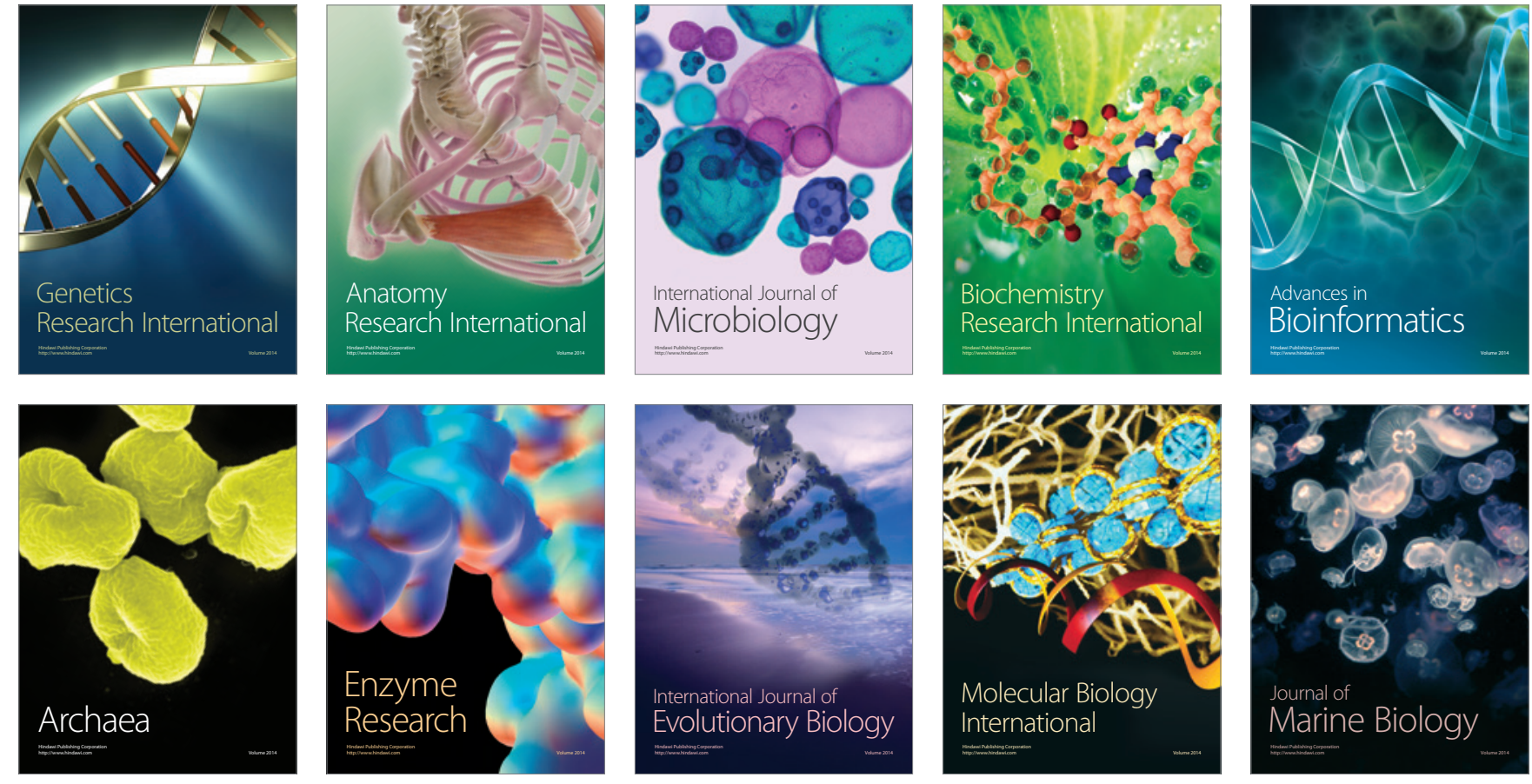